\title{
REVIEW
}

\section{Temperature, latitude and reproductive effort}

\author{
Andrew Clarke \\ British Antarctic Survey, NERC, High Cross, Madingley Road, Cambridge CB3 OET, United Kingdom
}

\begin{abstract}
The traditional IBP formulation of the energy budget is unsuitable for many marine organisms, partly because it sets production and respiration as alternative sinks when in reality they are linked but also because it fails to recognise the heterogeneous nature of respiratory demand. The various components of total respiration reflect separate demands for ATP which are likely to differ in their response to temperature and season. Such subdivision of total respiration emphasizes the difference between reproductive effort ( $R E$, that fraction of the total energy flux diverted to reproduction) and reproductive output (RO, weight-specific gonad production) as measures of reproductive energetics. Model calculations demonstrate that the variation of basal metabolic rate with temperature (and hence latitude) influences both RE and RO, but in differing ways. If annual RE is assumed to be roughly constant in tropical, temperate and polar populations, then for organisms of similar size and ecology annual RO will decrease with increasing latitude. Conversely if RO remains constant then annual RE will increase at high latitudes. Similar arguments predict an increase in net growth efficiency at low temperatures. When lifetime RE is considered in relation to the slower growth rates and increased age of first breeding frequent at high latitudes, then data for the caridean shrimp Pandalus borealis suggest the possibility that there is a balance between basal metabolism and growth rate, resulting in a relatively constant lifetime RE across the latitudinal range. Clearly rather than there being a simple competition between growth and reproduction, energy is divided between several competing sinks which include the costs of maintenance and activity.
\end{abstract}

\section{INTRODUCTION}

Consideration of the manner in which an organism divides incoming energy between growth and reproduction has played a central role in the development of life-history theory. It is conventional to regard these 2 forms of production as sinks competing for acquired energy (Gadgil \& Bossert 1970, Reznick 1983, Calow 1985, Sibly \& Calow 1986). When considering broad patterns of life-history and their energetic consequences, however, it is too simplistic to view matters purely as a trade-off between growth and reproduction. For all living organisms there is a cost to merely staying alive, usually termed basal or maintenance metabolism. This cost is significant and it varies with temperature.

It is the purpose of this paper to examine the influence of temperature, and hence latitude, on the fraction of the total energy intake that is diverted to reproduction. The argument is developed using model calcula- tions and then compared with available data for marine invertebrates. In order to clarify matters, however, it is necessary first to discuss the formulation of the energy budget in marine organisms.

\section{THE ENERGY BUDGET}

\section{Adaptation and acclimation}

Many marine organisms are remarkably tolerant of short-term changes in temperature. This is particularly true for shallow-water marine invertebrates and fish from temperate regions, and these organisms have been much studied as a result. Data from such studies are frequently then extrapolated to consideration of long-term (evolutionary) adaptation to temperature; however, these 2 processes differ not only in their time scale, but also sometimes in the mechanisms involved (for a fuller discussion see Clarke 1983, in press). In this 
paper I am considering only evolutionary adaptation to temperature, that is the energetic consequences of the evolution of genetically fixed variations in basal metabolic rate associated with compensation for mean environmental temperature. Clearly, altering the ambient temperature of a eurythermal organism will affect metabolic rate, growth and other physiological processes, but these short-term responses are not considered here.

\section{A physiological approach to the energy budget}

Most of the energy budgets published for marine organisms have used the formulation suggested for the International Biological Program (IBP) (Phillipson 1966, 1975, Crisp 1971, Klekowski \& Duncan 1975), in which consumption

$$
\mathrm{C}=\mathrm{P}+\mathrm{R}+\mathrm{U}+\mathrm{F}
$$

where $\mathrm{P}=$ production (both somatic and reproductive); $R=$ respiration; $U=$ excretion; and $F=$ faeces. The units chosen are usually those of energy although budgets are occasionally expressed in terms of specific elements such as carbon or nitrogen. Despite its wide use, however, the IBP formulation of the energy budget is inappropriate for studies of many marine organisms.

A major cause of difficulty is the respiration term, $R$. Respiration represents the energy used by the organism for work and it is a measure of the heat lost to the environment. Klekowski \& Duncan (1975) defined R as 'the energy required for the maintenance of life', and placed respiration in a clear thermodynamic context. They emphasized that the respiration rate measured at any given time is composed of inputs from mechanical work, work in chemical synthesis and the costs of active transport. Klekowski \& Duncan also added to $\mathrm{R}$ the specific dynamic action (SDA), although they noted that if the correct explanation of SDA was the metabolic cost of synthesising new macromolecules then this was already included within the respiration term. The cost of locomotor activity was not, however, included. This and other early definitions of $\mathrm{R}$ recognised clearly the heterogeneous nature of respiration; that is although $R$ is essentially a measure of the demand for ATP, this ATP is used for a variety of separate physiological processes.

Physiologists concerned with the effects of temperature, however, have traditionally classified respiration differently, either as active respiration (which includes the cost of mechanical work involved in locomotor activity) or standard (resting) respiration (which does not). Standard respiration is frequently viewed as a single process, a measure of 'metabolism', and moreover a process which would be expected to show com- pensatory adjustments (both seasonal and evolutionary) to temperature change. The selective value of such adjustments to 'metabolism' is not always clear and this approach has led to a certain amount of confusion as to what is actually involved in temperature adaptation, together with a large and unwieldy nomenclature (Clarke in press).

Any physiological approach to the energy budget must take into consideration this heterogeneous nature of respiration, and allow for the possibility that each of the separate processes may vary differently with season or temperature. The respiration component of the energy budget equation is therefore better considered as a summation term, $\Sigma R$, which represents the total demand for oxygen:

$$
\Sigma R=R_{b}+R_{s}+R_{g}+R_{a}
$$

where $R_{b}=$ oxygen required for basal (maintenance) metabolism; $R_{s}$ and $R_{g}=$ respiratory costs of the synthesis of somatic and gonad tissue respectively; and $R_{a}=$ oxygen required to fuel locomotor activity. Standard (resting) respiration, $R_{\text {std, }}$ is thus:

$$
\mathrm{R}_{\mathrm{s} t d}=\mathrm{R}_{\mathrm{b}}+\mathrm{R}_{\mathrm{s}}+\mathrm{R}_{\mathrm{g}}
$$

This physiological breakdown of total respiration is shown schematically in Fig. 1a, where the various divisions of the energy budget have been grouped together into a number of physiological sinks. Thus $\left(P_{s}+R_{s}\right)$ represents the total cost to the organism of producing somatic tissue, not just the energy equivalent of the newly synthesised tissue $\left(\mathrm{P}_{\mathrm{s}}\right)$ but also the respiratory cost of producing that tissue $\left(R_{\mathrm{s}}\right)$. There is a similar respiratory cost $\left(R_{g}\right)$ to producing new reproductive tissue.

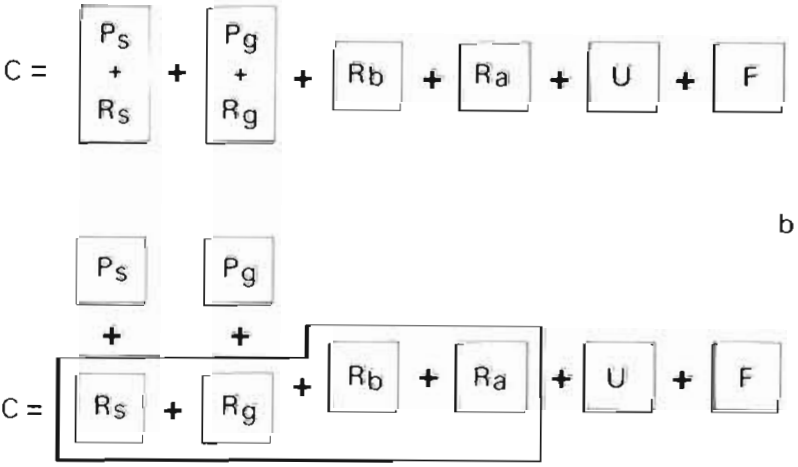

Fig. 1. Diagrammatic representation of the energy budget for a representative marine invertebrate. $C$ : consumption; $P_{s}$ : somatic production; $\mathrm{P}_{\mathrm{g}}$ : gonad production; $\mathrm{R}_{s}$ and $\mathrm{R}_{\mathrm{g}}$ : respiratory costs of somatic and reproductive production respectively; $R_{b}$ : basal (maintenance) metabolism; $R_{d}$ : respiratory cost of locomotor activity; U: excretion; F: faeces. (a) Energy budget partitioned into the major physiological sinks. (b) Energy budget as most frequently measured; the bold line encloses those respiratory processes usually measured together 
The respiratory costs of synthesis, $R_{g}$ and $R_{s}$, represent the fact that the synthesis of biological macromolecules is not $100 \%$ efficient and requires ATP. The synthesis of a single peptide bond, for example, costs 4 ATP molecules (or about 4.5 if costs of mRNA recycling are taken into account: Kiørboe et al. 1985). There are also costs to transport of precursors and the secretion of finished products. The overall efficiency of synthesis will depend on the biochemical composition of the particular tissue and is imperfectly known. An accepted working figure is 0.8 , that is it costs roughly $100 \mathrm{~kJ}$ to produce $80 \mathrm{~kJ}$ of new biomass, the missing 20 $\mathrm{kJ}$ being lost as heat. (For a full discussion see Parry 1983). During periods of growth or gametogenesis there will therefore be an increase in oxygen consumption due to the respiratory costs of synthesis.

In Fig. 1a basal metabolism is shown as $R_{b}$ with no corresponding mass term. This is because basal metabolism involves the turnover of existing biomass, together with the costs of osmoregulation, basal neural activity and so on (Clarke 1980, 1983). It involves no increase in biomass, for any such increase would be growth.

The physiological energy budget shown in Fig. 1a is a theoretical ideal and there are severe practical problems in measuring the individual components as shown. The major difficulty is that it is virtually impossible to distinguish the various components of $\Sigma \mathrm{R}$ by experiment. All that can be measured is the oxygen consumption of an organism at any given time, represented in Fig. 1 b by the large box encompassing $R_{s}$, $R_{\mathrm{g}}, \mathrm{R}_{\mathrm{b}}$ and $\mathrm{R}_{\mathrm{a}}$.

The most difficult term to estimate is $R_{a}$, the cost of locomotor activity. In few published energy budgets for marine invertebrates has this term been explicitly considered although in many pelagic species it must be significant. (A notable exception is a recent energy budget for the infaunal bivalve Macoma balthica which includes estimates of the costs of deposit feeding and suspension feeding as well as maintenance metabolism: Hummel 1985). One possible approach is to measure the oxygen consumption of a quiescent animal (usually termed standard metabolism and often taken as an approximation to basal metabolic rate), and then also to determine the relationship between locomotor activity and oxygen demand. This technique has been used extensively with fish (see for example Brett \& Groves 1979) and a few active pelagic crustaceans (Torres et al. 1982, Torres \& Childress 1983). Before these data can be integrated into a total energy budget, however, information is also needed on the pattern of activity in the wild. Such data are almost never available, although for many marine organisms we know enough to be sure that $R_{a}$ is an important component of the annual energy budget; the cost of activity cannot be ignored simply because it is difficult to measure.

An approximation that is frequently applied (particularly in zooplankton) is to measure routine oxygen demand, this being the respiration rate at a level of activity believed to be representative of normal existence. It is thus greater than basal metabolism but below the maximum sustainable level of activity. Without knowledge of the annual pattern of activity in the wild of the organism under investigation, however, it is still impossible to assess how representative such a measure really is. Field studies of total metabolic rate by elimination of ${ }^{65} \mathrm{Zn}$ from snails have suggested that metabolic rates in the wild are at least twice those measured in the laboratory (Mishima \& Odum 1963), the difference presumably being due to activity. A similar result has been demonstrated for plaice (Edwards 1967, Edwards et al. 1969).

The $F$ term in the energy budget represents the energy content of material which has been ingested, but which is not assimilated through the gut wall. It therefore includes material regurgitated from the stomach as well as true faeces (Clarke 1979a). The U term represents material assimilated but later excreted as nitrogenous waste products, together with products such as mucus. In some organisms the waste products are voided with the faeces, making a separate determination of $F$ and $U$ impossible. This difficulty has resulted in 2 quite separate definitions of assimilation, a dichotomy which also affects the calculation of ecological growth efficiencies.

In strict physiological terms the energy assimilated, A, must include everything which is taken through the gut wall, whatever its subsequent fate. Thus:

$$
\mathrm{A}=\mathrm{P}_{\mathrm{s}}+\mathrm{P}_{\mathrm{g}}+\mathrm{SR}+\mathrm{U}
$$

The assimilation efficiency, $a$, is then defined by:

$$
\mathrm{a}=\mathrm{A} / \mathrm{C}
$$

In many texts an alternative estimate of the energy assimilated is proposed (for example, Klekowski \& Duncan 1975); here the energy assimilated is approximated by summing total production and respiration:

$$
A^{\prime}=P_{g}+P_{s}+\Sigma R
$$

and, as before:

$$
\mathrm{a}^{\prime}=\mathrm{A}^{\prime} / \mathrm{C}
$$

Crisp (1971) has termed A absorption and A' assimilation. Clearly $\mathrm{A}^{\prime}$ and $\mathrm{a}^{\prime}$ are different from the true values A and $a$, for they take no account of U. Excretion, however, can be an important component of the energy budget of many marine organisms. For example, mucus can account for about $10 \%$ of ingested energy in many gastropods (Hughes 1986) and up to $30 \%$ in the European ormer Haliotis tuberculata (Peck 1983). 


\section{Seasonality and the energy budget}

A physiological approach to the energy budget equation draws attention to a number of seasonal aspects of energy flow not immediately obvious from the more traditional IBP formulation, but which are important to the measurement of reproductive effort and growth efficiencies in marine organisms.

In many temperate and most polar marine invertebrates growth and reproduction are seasonal, being confined to those months when food is available (usually summer). Associated with this will therefore be a seasonal increment in $\Sigma \mathrm{R}$ due to the costs of synthesis, $R_{s}$ and $R_{g}$. Parry (1978) has shown that in the limpet Cellana tramoserica these costs alone can explain all of the observed increment in respiration during the growing season. Parry (1983) has further suggested that seasonal variations in growth may explain most of the observed seasonal patterns of respiration in marine invertebrates, including many previously interpreted as seasonal acclimatisation to temperature. An increase in respiration in summer purely as a response to a higher temperature is not adaptive in itself, for it would be needlessly wasteful of energy which must be obtained from reserves or an increased food intake. Equally a 'compensatory' increase in oxygen uptake in winter as a response to lower temperatures is meaningless; it merely means that physiological processes are operating faster for no reason. In both cases selection will tend to minimise the costs of maintenance metabolism, $R_{b}$, and hence reduce the temperature sensitivity of this process. Viewing seasonal variations in oxygen consumption as a reflection of seasonal changes in growth rate and/or gametogenesis is a simpler hypothesis. It also makes more sense physiologically.

Since synthesis carries a respiratory cost, the rate of new tissue production, $\Delta\left(\mathrm{P}_{\mathrm{s}}+\mathrm{P}_{\mathrm{g}}\right) / \Delta \mathrm{t}$, will clearly influence oxygen consumption because of the contributions from $R_{s}$ and $R_{g}$. There will thus be a positive correlation between measures of production and measures of respiration, since these processes are intimately related. Such a relation was first demonstrated by Engelmann (1966) and then documented more comprehensively by McNeill \& Lawton (1970). The extent of this coupling will clearly depend on the fraction of $\Sigma R$ contributed by $R_{s}$ and $R_{g}$. In cold-water forms, where $R_{b}$ is low (and particularly sessile benthic invertebrates, where $R_{a}$ is also low) the correlation between respiration and production will be very strong; in active, warm-water species it will be much weaker.

There is increasing evidence that, at least in discontinuous feeders, growth tends to occur in a pulse immediately following a meal. The respiratory cost of growth may thus explain much of the post-prandial increase in oxygen consumption (the specific dynamic action, SDA: Jobling 1981, 1983), and perhaps nitrogen excretion (Bayne \& Scullard 1977). In the starfish Asterias rubens, for example, there is a strong correlation between the extent of SDA and overall growth rate (Vahl 1984). In organisms with a strong seasonal variation in growth rate, this situation may be modified hormonal or other higher level controls, resulting in a longer-term elevation of oxygen demand (including possibly also a component of increased basal turnover, $\mathrm{R}_{\mathrm{b}}$ ), even in organisms subjected to a short term deprivation of food such as before an experiment.

\section{Reproductive effort}

Using the physiological formulation of the energy budget shown in Fig. 1a, the annual reproductive effort (RE) of an individual mature organism is given by:

$$
R E=\left(P_{g}+R_{g}+R_{a b}\right) / A
$$

where $R_{a b}=$ cost of behavioural activity associated with reproduction, and all components are summed over the full year (Tinkle \& Hadley 1975). This is a widely accepted definition of reproductive effort, although it takes no account of costs such as later mortality consequent on investment in reproduction (Calow 1979, Tuomi et al. 1983, Sibly \& Calow 1986). Where the costs of behavioural activity are sufficiently low (a typical example might be a sessile benthic organism releasing gametes directly into the water) then $R_{a b}$ may be taken as zero. The value of $R_{a b}$ has yet to be determined for any marine invertebrate, although in many species the cost of activity associated with reproduction can be substantial. Examples are crustaceans which carry the female in amplexus for extended periods of time, organisms which engage in fighting or territorial behaviour and invertebrates which brood their eggs or young. For example, in the shrimp Palaemon adspersus non-breeding females grow much faster than females brooding eggs when both are fed to satiation (Berglund \& Rosenqvist 1986).

Since somatic growth and reproduction can proceed together, direct measurement of $R_{\mathrm{g}}$ is technically very difficult. Parry $(1978,1983)$ has suggested a general figure for the thermodynamic efficiency of synthesis of 0.67 and Kiørboe et al. (1985) calculated a value of 0.8 for Acartia tonsa. These values of efficiency can then be applied to measures of biomass produced $\left(\mathrm{P}_{g}\right)$ to calculate the associated respiratory costs $\left(R_{g}\right)$.

It has long been recognised that annual reproductive effort as defined above is very difficult to measure, for it involves a great deal of detailed physiological work. Instead, annual reproductive effort is frequently estimated by measuring annual weight-specific gamete 
production (Pianka 1972), which may be termed reproductive output $(\mathrm{RO})$. If the mean biomass of an individual organism over the year under study is $B$, then the annual individual reproductive output during that year is given by:

$$
\mathrm{RO}=\mathrm{P}_{\mathrm{g}} / \mathrm{B}
$$

Clearly $R E$ and $R O$ are very different measures. The value of $R E$ is influenced by all other energetic processes in the organism (summed as A), whereas RO involves only $\mathrm{P}_{g}$ and $\mathrm{B}$. True reproductive effort, $\mathrm{RE}$, will therefore be influenced by changes in energetic parameters which influence neither $P_{g}$ nor $B$ and hence leave $\mathrm{RO}$ unaffected. One such change is the variation of basal metabolic rate, $\mathrm{R}_{\mathrm{b}}$, with mean habitat temperature (and hence latitude). The potential effects of this variation on $\mathrm{RE}$ and $\mathrm{RO}$ are examined in the following section.

\section{TEMPERATURE AND REPRODUCTIVE EFFORT}

\section{Assumptions in the model}

In performing the following model calculations it has been assumed that:

(1) For all physiological processes natural selection has resulted in the evolution of more or less perfect compensation for temperature. That is to say, all other things being equal, any given physiological process will proceed at roughly the same pace in polar, temperate and tropical organisms.

(2) The metabolic costs of synthesising a given amount of protein, lipid, carbohydrate or any other cellular constituent do not vary with temperature, at least over the physiological range $(-2$ to $40>C)$, and that the overall thermodynamic efficiency of tissue synthesis is 0.7 .

(3) Basal metabolic rate, $R_{b}$, varies with environmental temperature as described by Ivleva $(1973,1977$. 1980).

\section{The evidence}

It is generally accepted that in marine organisms there has been a general evolution of compensation for temperature in locomotor ability and general metabolism (Clarke in press). Polar, temperate and tropical regions all contain both active and sedentary species and there is no persuasive evidence of any latitudinal cline in overall metabolic organisation. (A possible exception is the increase in lipid storage in pelagic marine invertebrates towards higher latitudes, but this is related to the increasingly seasonal pattern of food availability rather than temperature per se and benthic animals show no such cline: Clarke 1983). Examples of compensation where the mechanism is clearly understood are, however, very few (Clarke in press).

Whether organisms show temperature compensation in growth is far more difficult to establish. Many polar organisms grow slowly or very slowly, and it has long been felt intuitively that this was an inevitable consequence of the low water temperatures. Nevertheless, a few polar species do grow quickly and in many species growth is rapid when sufficient food is available. I have argued elsewhere (Clarke 1980,1983) that where overall growth rates are slow, this does not reflect any direct temperature limitation of the biochemical processes involved in growth but is rather a consequence of a severe seasonal pattern in the availability of food. There have, however, been very few investigations of latitudinal or temperature compensation for growth in marine organisms.

Ament (1979) has demonstrated compensation for temperature in the growth rates of larvae of 3 species of Crepidula from populations living at different temperatures. Also Levinton (1983) has shown that northern (colder water) populations of the dorvilleid polychaete Ophryotrocha costlowi grow faster than the more southerly $O$. macrovifera. Careful laboratory rearing experiments over several generations indicated that these differences in growth rate are genetically based. A similar compensation has been demonstrated in the estuarine harpacticoid copepod Scottolana canadensis (Lonsdale \& Levinton 1985).

The question of whether costs of synthesis might vary with temperature appears never to have been examined. In the absence of any evidence it has therefore been assumed that the overall thermodynamic efficiency of tissue synthesis of 0.67 suggested by Parry $(1978,1983)$ is a good approximation.

The relationship between respiration rate and temperature has attracted a great deal of attention over the years (see summary in Clarke 1983). The most comprehensive investigations have been those of Ivleva $(1973,1977,1980)$, whose analyses were based on all available data for crustacean zooplankton, and Ikeda $(1970,1974,1985)$. These and all previous studies have demonstrated a positive relation between respiration rate and temperature. The enormous variety of organisms investigated together with the variety of techniques used, however, make detailed interpretation of these relations difficult. Basal metabolic rate, $R_{b}$ undoubtedly contributes substantially to the measured respiration rate and I have suggested elsewhere that the overall trend expresses an underlying relation between $R_{b}$ and temperature (Clarke 1983). In all planktonic species, however, there will have been some contribution from the metabolic cost of swimming. This cost can be significant (Torres et al. 1982, 
Torres \& Childress 1983) but there is no reason to suppose that it varies with habitat temperature.

For the purposes of the following calculations the curve presented by Ivleva (1980) has been taken as expressing the general shape of the relation between $\mathrm{R}_{\mathrm{b}}$ and mean environmental temperature (Fig. 2). A value of $R_{b}$ for an organism living at one temperature may therefore be used to calculate a value of $R_{b}$ for $a$ hypothetical related organism of similar size and ecology living at a different environmental temperature.

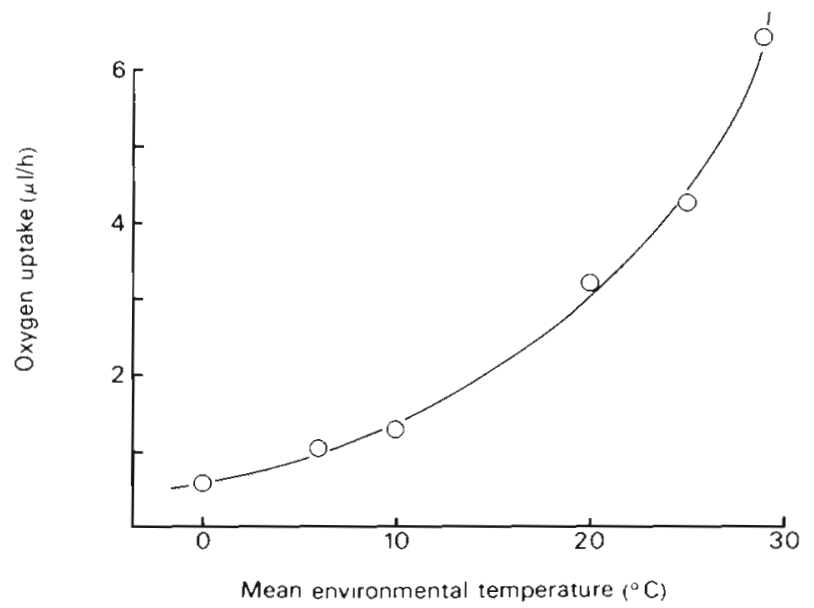

Fig. 2. Relation between respiration rate and mean environmental temperature for marine crustaceans established by Ivleva $(1973,1977,1980)$

When this is done, the corresponding variation in the other parameters of the overall energy budget (for example true reproductive effort, $R E$, weight-specific gamete output, RO, or ecological growth efficiency) may be examined. Simple cases would be to examine the variation in annual RE when $R O$ is held constant and $R_{b}$ allowed to vary with temperature, and then to look at variation in $\mathrm{RO}$ with $\mathrm{RE}$ held constant under the same conditions. This is done in the following 2 sections.

\section{Variation of annual RE with temperature}

All calculations have been based on published energy budgets for marine invertebrates. In the literature these budgets are presented using different units and definitions, but all are based essentially on the traditional IBP formulation. For the purposes of the present calculations, all the data have been recalculated to partition the data for total respiration, $\Sigma \mathrm{R}$, into its various components $\left(R_{s}, R_{g}, R_{b}\right.$ and $\left.R_{a}\right)$ as follows. $R_{s}$ and $R_{g}$ were calculated from the annual values of $P_{s}$ and $P_{g}$, assuming a thermodynamic efficiency of $0.7 . R_{a}$ for bivalves was taken to be $0.2 \mathrm{R}_{\mathrm{b}}$, and in crustaceans $0.5 R_{b}$. These assumptions are entirely arbitrary, for there are virtually no data available with which to assess the annual cost of locomotor and other activity in these organisms. Next a value for $R_{b}$ was calculated from $\Sigma R$ by substituting the estimated values of $R_{s}, R_{g}$ and $R_{a}$. Hypothetical values for $R_{b}$ at other environmental temperatures were then calculated according to Ivleva's curve.

Assuming that weight-specific gamete production remained constant at all temperatures (that is $P_{g}, R_{g}, P_{s}$ $R_{s}$ and $B$ remained constant), and that there was no variation in $R_{a}$, a theoretical annual reproductive effort (RE) could be calculated for all temperatures. A representative result is shown in Fig. 3. The pattern of variation was similar for all organisms examined, since this is determined essentially by the relation between $\mathrm{R}_{\mathrm{b}}$ and temperature. Using data for the limpet Cellana tramoserica (Parry 1978) and holding annual RO con-

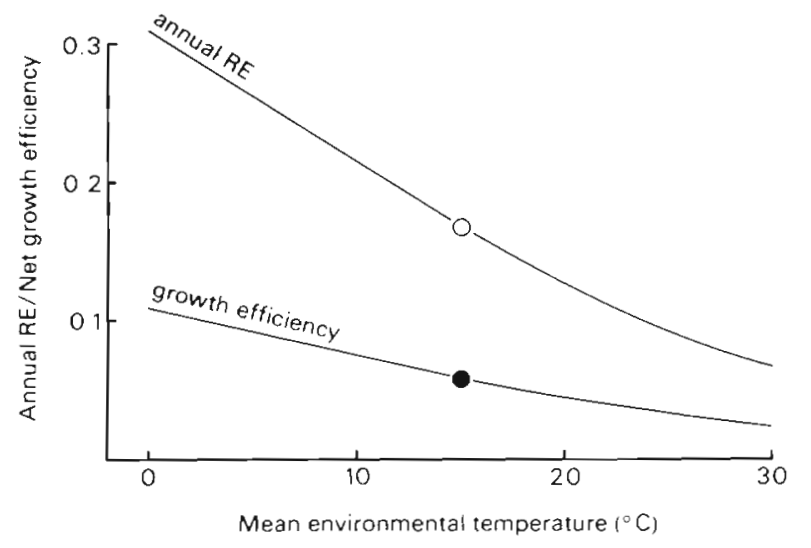

Fig. 3. Variation in annual true reproductive effort, RE (0) and net ecological growth efficiency, $K_{2}(\bullet)$ with mean environmental temperature for a cline of hypothetical limpets with annual weight-specific gonad output held constant. Based on data for Cellana tramoserica Parry $(1978,1982)$; circles show actual data calculated as described in text, lines show theoretical variation with temperatuse (and hence latitude)

stant at 2.85, annual RE would vary from 0.31 in an hypothetical polar population of Cellana to 0.07 in a hypothetical tropical population, a range of $\times 4.4$. Variations in those parameters fixed more or less arbitrarily (such as the efficiencies of synthesis or the cost of activity) altered the numerical results of the calculations, but not the overall pattern.

\section{Variation of RO with temperature}

A similar exercise may be performed by holding annual reproductive effort ( $R E$ ) constant and plotting the resultant variation in annual weight-specific gonad output (RO) with temperature and, by inference, latitude (Fig. 4). Under these conditions, annual weight-specific gonad output (RO) is lowest for a hypothetical polar population of Cellana (about 0.6) 


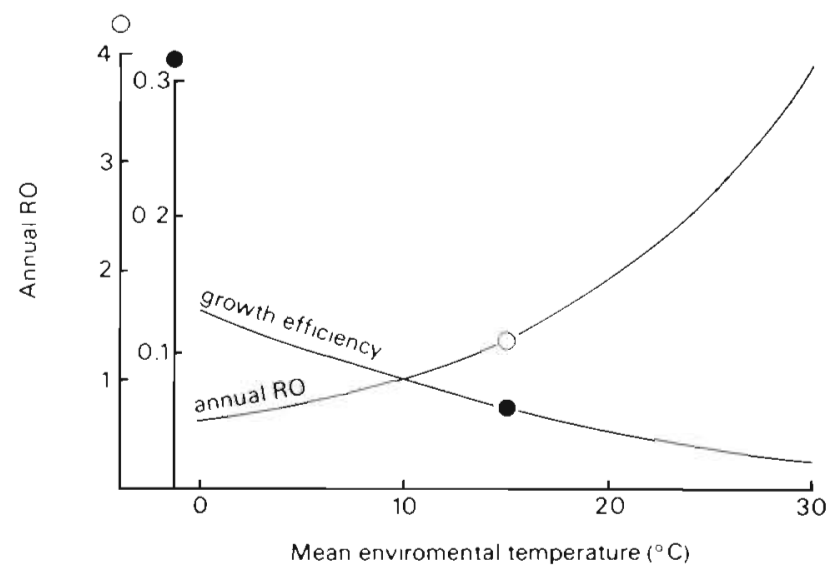

Fig. 4. Variation in annual weight-specific gonad output, RO $(0)$ and net ecological growth efficiency, $K_{2}(\bullet)$ with mean environmental temperature for a cline of hypothetical limpets with true annual reproductive effort held constant. Calculation and presentation as for Fig. 3

and highest in the hypothetical tropical population (about 3.9), a range of about $\times 6.5$. Under both sets of model conditions ( $R O$ constant and RE constant) the ratio tropical/polar varied with species and the values of the arbitrarily fixed parameters; however the qualitative results, that is the overall shape of the relation, was always the same.

\section{Reproductive output and latitude: real data}

The 2 cases outlined above may be regarded as extremes. Selection acting on natural populations evolving to cope with the range of variables associated with habitats ranging from the tropics to the poles will have acted upon both true reproductive effort and reproductive output.
Available data for the annual weight-specific egg production of female caridean shrimps from temperate and polar waters are summarised in Table 1. Data for crangonids, pandalids and hippolytids have been separated from each other, for these groups have different ecology, size and reproductive biology (Clarke 1979b). Data for pandalid and hippolytid shrimp suggest that the annual RO of polar species is only about 60 to $70 \%$ that of the temperate species (the differences all being significant at the level $p=0.01$ ). This reduction of annual $\mathrm{RO}$ in colder-water species is similar to that predicted in the model calculations presuming annual $\mathrm{RE}$ to be constant. The annual reproductive efforts of polar and temperate shrimps may thus be more similar than measurements of weight-specific gonad output would suggest. The data for crangonid shrimps also suggest a lower RO in polar species. There are several other reports in the polar literature of a reduced reproductive output in polar species. Unfortunately most of these are anecdotal rather than quantitative, but it does appear that this trend may be general for several phyla (for recent summaries see Picken 1979, Clarke 1982). A vast literature exists on the gonad size of benthic molluscs but site to site variations due to local fluctuations in food availability are so large that no latitudinal cline can be detected. Recently Andrew (1986) has shown the influence of food availability on gonad output in the echinoid Evechinus chloroticus.

\section{Growth efficiency and latitude}

The 2 ecological growth efficiencies calculated most frequently, $K_{1}$ and $K_{2}$, are usually defined as:

$$
\mathrm{K}_{1}=\mathrm{P}_{\mathrm{g}} / \mathrm{C} \text { and } \mathrm{K}_{2}=\mathrm{P}_{\mathrm{g}} / \mathrm{A}
$$

Table 1. Comparison of annual weight-specific gonad output (annual reproduction output, RO) in polar and temperate caridean shrimps. RO calculated as (fresh weight newly spawned eggs, g)/(fresh weight female, g); data presented as mean and standard deviation ( $\mathrm{SD} ; \mathrm{n}=$ no. of individuals analysed). Data for temperate and Antarctic species from Clarke (1979b); data for A.rctic species: Clarke \& Hopkins (unpubl. data)

\begin{tabular}{|c|c|c|c|c|}
\hline \multirow[t]{2}{*}{ Species } & \multicolumn{3}{|c|}{ Annual RO } & \multirow[t]{2}{*}{ Remarks } \\
\hline & Mean & $\mathrm{SD}$ & $\mathrm{n}$ & \\
\hline \multicolumn{5}{|l|}{ PANDALIDAE } \\
\hline Pandalus borealis & 0.177 & 0.024 & 95 & Arctic; Isfjord, Svalbard, 1984 \\
\hline Pandalus montagui & 0.242 & 0.056 & 39 & Temperate; the Wash, UK, 1976 \\
\hline \multicolumn{5}{|l|}{ HIPPOLYTIDAE } \\
\hline Chorismus antarcticus & 0.171 & 0.018 & 28 & Antarctic; South Georgia, 1972 \\
\hline Lebbeus polaris & 0.131 & 0.034 & 132 & Arctic; Isfjord, Svalbard, 1985 \\
\hline \multicolumn{5}{|l|}{ CRANGONIDAE } \\
\hline Crangon crangon & 0.165 & 0.033 & 68 & Temperate; UK, 1977 \\
\hline Notocrangon antarcticus & 0.118 & 0.014 & 23 & Antarctic; South Georgia, 1978 \\
\hline Sabinea septemcarinata & 0.136 & 0.060 & 29 & Arctic; Isfjord, Svalbard, 1985 \\
\hline
\end{tabular}


These 2 measures have been given a variety of names (see Brafield \& Llewellyn 1982, for a list) but $K_{1}$ is usually referred to as the gross growth efficiency and $\mathrm{K}_{2}$ as the net growth efficiency. $\mathrm{K}_{1}$ and $\mathrm{K}_{2}$ are ecological growth efficiencies, a measure of what a given organism does with the energy it derives from its food. They are quite distinct from the thermodynamic efficiencies of synthesis discussed earlier, which are measures of the efficiency of the synthetic process itself.

Since $K_{1}$ and $K_{2}$ are measures of that fraction of the total energy intake which is diverted into somatic growth, they are analagous to RE and by an identical series of arguments to those used above it can be shown that, all other things being equal, ecological growth efficiencies should be greater at lower temperatures (that is, at higher latitudes: Fig. $3 \& 4$ ). This is essentially because the lower basal metabolic rate in polar species means that for any given amount of food consumed, a relatively greater proportion can be directed to growth, less being lost to maintenance (Clarke 1983). Some evidence for this has been presented by Luxmoore (1985) who compared the growth efficiency of the Antarctic marine isopod Serolis polita with those of other marine isopods. These data were summed over a whole year. Since growth in $S$. polita is confined to the summer when food is most abundant (Luxmoore 1985), growth efficiencies calculated over the period of growth alone will be very high indeed. These are the only data available for polar marine invertebrates and many more studies are needed to establish whether high growth efficiencies are indeed a general characteristic of polar forms.

To make the values of $K_{1}$ and $K_{2}$ truly comparable with the measure of RE defined earlier, they should also include the respiratory costs of synthesis, so that for example $K_{2}=\left(P_{s}+R_{s}\right) / A$. This, however, is almost never done, probably because ecological growth efficiencies are used as a measure of the transfer of energy from prey to predator. It is thus $\mathrm{P}_{\mathrm{g}}$ that is the important component, for this is the fraction of somatic production that is available to the next trophic level ${ }_{i} R_{s}$ is merely lost to the system as heat.

\section{DISCUSSION}

\section{Effects of seasonality on energy partitioning}

The above analyses (Fig. $3 \& 4$ ) have explicitly been confined to the annual energy budget of a representative sexually mature individual female. In this clearly delimited context a measurement of weight-specific gonad production is useful because it allows comparison of the annual gamete production of species from different latitudes (Table 1). However, in polar species not only does $R O$ tend to be reduced but so is annual growth rate and basal metabolic rate. As a result the annual energy intake of a polar species is considerably less than that of a related temperate species of similar size and ecology (Clarke 1980, 1983).

In most animal populations the annual intake of energy by an individual organism appears to be limited primarily by the availability of food and there is now a large body of data documenting the effects of food quantity on the growth rate and gamete production of wild populations of marine organisms (e.g. Andrew 1986). Moving from lower to higher latitudes this food is, for the lower levels of the marine food web, increasingly seasonal. In polar regions this tends to limit both growth and gonad production to the summer season when food is available. In some polar organisms, gonad production requires 2 successive summer periods for there will be little food available for gonad synthesis during the intervening winter (for example, the Southern Ocean isopod Serolis polita: Luxmoore 1982). Clearly in a case such as this, the concept of a simple evolutionary trade-off between growth and reproduction is unrealistic. Extending gonad production to a second summer incurs the cost of an extra period of basal metabolism, $R_{b}$, even when there is no growth or gametogenesis over winter. The cost of locomotor activity, $R_{a}$ may also be a significant component in nekton or plankton. For example, Koch \& Weiser (1983) have shown that in roach Rutilus rutilus there is a significant decrease in swimming activity during the period of gonad production.

Clearly for most aquatic organisms energy absorbed is simply not divided between growth and reproduction but rather between 4 major competing sinks: growth, reproduction, maintenance and activity (Fig. 5). When comparative studies are undertaken between species from similar thermal regimes whose size and ecology are similar, differences in $R_{a}$ and $R_{b}$ may be small and hence ignored. Under these limited conditions, differences in life-history phenomena may indeed be explicable in terms of a trade-off between growth and repro-

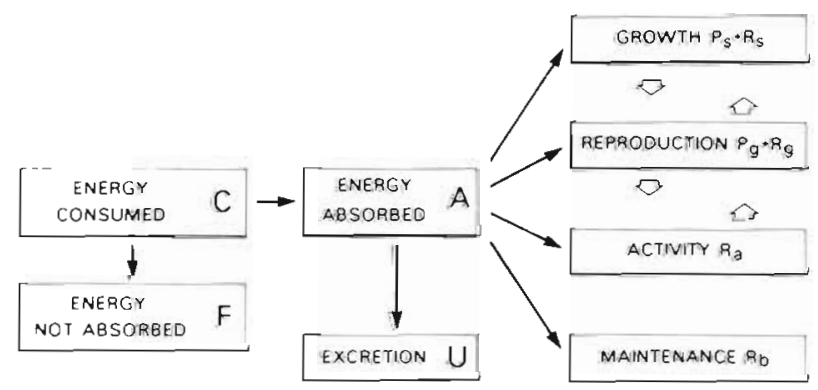

Fig. 5. Representation of the major competing physiological sinks in the energy budget of a marine organism 
duction. However, when comparisons are made between species from different habitats, from different latitudes, or when the species in question differ in size or ecology, than consideration must be given to all physiological energy sinks, not just growth and reproduction. The situation becomes even more complex when lifetime energetics are considered.

\section{Annual versus lifetime $\mathrm{RE}$}

For 2 species growing to the same size, having similar rates of basal metabolism and weight-specific gonad output ( $\mathrm{RO}$ ) at maturity, the true lifetime RE of the slower growing species will be lower because of the greater amount of energy directed to maintenance and activity during the longer lifespan. Organisms with distributions covering a latitudinal cline tend to have longer lifespans, slower growth rates and lower basal respiration rates at higher latitudes (Clarke 1983). Clearly the lifetime RE of any given population (assuming $\mathrm{RO}$ and other factors remain approximately equivalent across the range) will depend on the balance between the increased lifespan and decreased basal metabolism associated with the lower temperature.

A useful species in which to examine this question is the northern deepwater shrimp Pandalus borealis. This has a wide latitudinal range, from the high Arctic to the North Sea in the eastern North Atlantic, and is an exceptionally well-studied organism because of its importance as a fishery. The age at first spawning in $P$. borealis ranges from just over $2 \mathrm{yr}$ in southern populations to $6 \mathrm{yx}$ in high Arctic populations (Rasmussen 1953, Appollonio \& Dunton 1969, quoted in Shumway et al. 1985). Age at first spawning thus shows a negative correlation with mean environmental temperature (although this is not necessarily an indication of a direct control of growth rate by temperature: Clarke 1983). The various components of a total energy budget may be estimated from a variety of sources (Table 2) and the relation between lifetime RE and environmental temperature determined (Fig. 6).

If basal metabolism is assumed to be the same for all populations of Pandalus borealis throughout its range then clearly there will be a strong positive correlation between lifetime RE and temperature. However, if basal metabolism is assumed to vary with temperature, then lifetime RE is independent of temperature, and hence latitude (Fig. 6: $F=2.92, p>0.10$ ). This suggests the possibility that across the range of $P$. borealis there is a balance between lifespan and basal metabolism resulting in a more or less constant lifetime RE.

This conclusion can be no more than tentative, however, because of the patchy nature of the available
Table 2. Pandalus borealis Kroyer 1838. Calculation of a representative energy budget. Data are calculated for a mature female breeding for the first time

Mean wet $w$ t of female at first spawning $8 \mathrm{~g}$

$\mathrm{P}_{\mathrm{s}}$, energy content $=42.387 \mathrm{~kJ}$

Respiratory costs of production, $\mathrm{Rs}=0.3 \mathrm{P}_{\mathrm{s}}=12.716 \mathrm{~kJ}$

Energy lost at moulting $=\left(\mathrm{P}_{\mathrm{s}}+\mathrm{R}_{\mathrm{s}}\right) / 10$ (arbitrary) $=5.510$ $\mathrm{kJ}$

Reproductive output of $P$. borealis in Isfjord, Svalbard $=$ 0.177 (Table 1)

Wet weight of egg mass $=1.416 \mathrm{~g}$

$P_{g}$, energy content of egg mass $=11.702 \mathrm{~kJ}$

Respiratory costs of production, $\mathrm{R}_{\mathrm{g}}=0.3 \mathrm{P}_{\mathrm{g}}=3.511 \mathrm{~kJ}$

Basal (maintenance) metabolism estimated by the mean resting oxygen consumption of adult $P$. borealis in Balsfjord, Norway, $0.029 \mathrm{ml}(\mathrm{g} \text { wet } \mathrm{wt})^{-1} \mathrm{~h}^{-1}$ (Seiring \& Hopkins pers. comm.). For a female of wet weight $8 \mathrm{~g}$, this represents an oxygen consumption of $0.232 \mathrm{ml} \mathrm{h}^{-1}$ at $3>\mathrm{C}$.

$\mathrm{R}_{\mathrm{b}}$, basal metabolism $=4.663 \mathrm{~J} \mathrm{~h}^{-1}$

$\mathrm{R}_{\mathrm{a}}$, cost of activity $=0.5 \mathrm{R}_{\mathrm{b}}$ (arbitrary) $=2.331 \mathrm{~J} \mathrm{~h}^{-1}$

For a first approximation in the calculation of lifetime energetics, growth from metamorphosis to first spawning is assumed to be linear, and both $R_{b}$ and $R_{a}$ to vary linearly with size. Excretion was ignored $(U=O)$.

\section{Conversion factors used}

$1 \mathrm{cal}=4.1864 \mathrm{~J}$

$1 \mathrm{ml}$ oxygen consumption equivalent to a loss of $20.097 \mathrm{~J}$ (Petrusewicz \& Macfadyen 1970)

$\%$ dry $w t$ in female $=23.15 \%$, in eggs $=35.58$ (Clarke unpubl. obs.)

Calorific value of females $=5.467 \mathrm{kcal}(\mathrm{g} \mathrm{dwt})^{-1}(\mathrm{Hop}-$ kins in Shumway et al. 1985)

Calorific value of eggs $=5.548 \mathrm{kcal}(\mathrm{g} \mathrm{dwt})^{-1}($ Hopkins ibid)

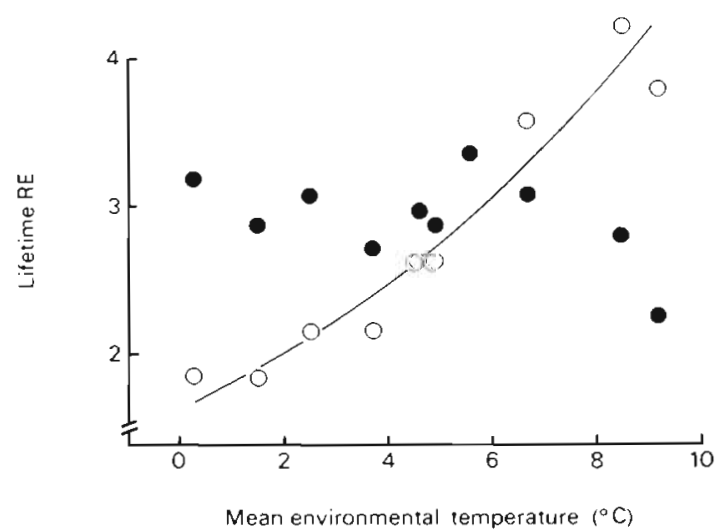

Fig. 6. Pandalus borealis. Variation of lifetime reproductive effort with mean environmental temperature. (0) Data calculated assuming no variation of basal metabolism with temperature; line fitted by least squares to logarithmically transformed data. (-) Calculated assuming basal metabolism varies with mean environmental temperature according to Ivleva (1973, 1977, 1980: see Fig. 2); this relation is not significant $(\mathrm{F}=2.92, \mathrm{p}>0.10)$ 
data. It would be extremely valuable to test this conclusion by making measurements of:

(1) Basal metabolism of Pandalus borealis from different populations, to see whether $R_{b}$ does indeed vary with mean environmental temperature as suggested by Ivleva (1980).

(2) Weight-specific gonad output (RO) of the various populations (in Fig. 6 this has been assumed not to vary with latitude).

(3) The cost of brooding eggs; this is unknown but may be important (Berglund \& Rosenquist 1986). Certainly the cost will vary with latitude, since brooding period varies with latitude.

In making realistic calculations of lifetime reproductive effort it is also necessary to take account of that proportion of the population which survive to breed twice or even 3 times. Any variations in the environment which influence these proportions (for example changes in the pattern of mortality) may also simultaneously influence other parameters via densitydependent mechanisms, an obvious example being weight-specific gonad output which is influenced by food availability and hence population density. The implications for either individual or population lifetime $\mathrm{RE}$ are thus by no means easy to predict.

\section{CONCLUSIONS}

Model calculations are of value only if either they may be tested against real data, or they suggest previously hidden aspects of biology. The theoretical analyses undertaken here suggest the following aspects of the relationship between temperature and energetics which are not immediately obvious. These are:

(1) The variation of basal metabolic rate with mean environmental temperature (and hence latitude) means that ecological growth efficiencies will be higher in cold-water forms.

(2) That weight-specific gonad output is not a valid comparative measure of true reproductive effort, particularly when comparing organisms from differing temperatures.

(3) That there may be a balance between lifespan and basal metabolism resulting in a relatively constant lifetime reproductive effort in populations with a wide latitudinal range.

Acknowledgements. I thank Lesley Holmes for undertaking the measures of reproductive output of Arctic shrimps, and Chris Hopkins, University of Tromso, for permission to use unpublished data for Pandalus borealis. I also thank Roger Hughes for valuable comments on an early draft of the manuscript, and Chris Hopkins and Ola Vahl for much useful discussion on the topic of reproductive energetics.

\section{LITERATURE CITED}

Ament, A. S. (1979). Geographic variation in relation to life history in three species of the marine gastropod genus Crepidula: growth rates of newly hatched larvae and juveniles. In: Stancyk, S. E. (ed.) Reproductive ecology of marine invertebrates. Univ. of South Carolina Press, Columbia, p. 61-76

Andrew, N. L. (1986). The interaction between diet and density in influencing reproductive output in the echinoid Evechinus chloroticus (Val.). J. exp. mar. Biol. Ecol. 97: $63-79$

Appollonio, S., Dunton, G. E. (1969). The northern shrimp. Pandalus borealis in the Gulf of Maine. Maine Department of Marine Research Completion Report, Project 3-12 12, p. $1-81$

Bayne, B. L., Scullard, C. (1977). An apparent specific dynamic action in Mytilus edulis L. J. mar biol. Ass. U.K. 57 371-378

Berglund, A., Rosenqvist, G. (1986). Reproductive costs in the prawn Palaemon adspersus: effects on growth and predator vulnerability. Oikos 46: 349-354

Brafield, A. E., Llewellyn, M. J. (1982). Animal energetics. Blackie, Glasgow and London

Brett, J. R., Groves, T. D. D. (1979). Physiological energetics. In: Hoar, W. S., Randall, D. J., Brett, J. R. (ed.) Fishphysiology, Vol. 8. Academic Press, New York, p. 279-352

Calow, P. (1979). The cost of reproduction - a physiological approach. Biol. Rev. 54: 23-40

Calow, P. (1985). Adaptive aspects of energy allocation. In: Tytler, P., Calow, P. (ed.) Fish energetics. Croom Helm, London, p. 13-31

Clarke, A. (1979a). Assimilation efficiency of the Antarctic marine isopod Glyptonotus antarcticus. Mar. Biol. 52: $157-160$

Clarke, A. (1979b). On living in cold water: K-strategies in Antarctic benthos. Mar. Biol. 55: 111-119

Clarke, A. (1980). A reappraisal of the concept of metabolic cold adaptation in polar marine invertebrates. Biol. J. Linnean Soc. Lond. 14: 77-92

Clarke, A. (1982). Temperature and embryonic development in polar marine invertebrates. Int. J. invert. Repr. 5: 71-82

Clarke, A. (1983). Life in cold water: the physiological ecology of polar marine ectotherms. Oceanogr. mar Biol. A. Rev. 21: $341-453$

Clarke, A. (in press). The adaptation of aquatic animals to low temperatures. In: Grout, B. W W.. Morris, E. J. (ed.) Low temperature biology. Edward Arnold, London

Crisp, D. J. (1971). Energy flow measurements. In: Holme, N. A., McIntyre, A. D. (ed.) Methods for the study of marine benthos. IBP Handbook No. 16. Blackwell, Oxford, p. $197-279$

Edwards, R. R. C. (1967). Estimates of the respiratory rate of young plaice (Pleuronectes platessa L.) in natural conditions using zinc-65. Nature, Lond. 216: 1335-1337

Edwards, R. R. C., Finlayson, D. M. Steele, J. H. (1969). The ecology of 0-group plaice and common dabs in Loch Ewe. II. Experimental studies of metabolism. J. exp. mar Biol. Ecol. 8: 299-309

Engelmann, M. D. (1966). Energetics, terrestrial field studies and animal productivity. In: Cragg, J. B. (ed.) Advances in ecological research, Vol. 3. Academic Press, London, p. 73-115

Gadgil, M., Bossert, W. H. (1970). Life historical consequences of natural selection. Am. Nat. 104: 1-24

Hughes, R. N. (1986). A functional biology of marine gastropods. Croom Helm, London 
Hummel, H. (1985). An energy budget for a Macoma balthica (Mollusca) population living on a tidal flat in the Dutch Wadden Sea. Neth. J. Sea Res. 19: 84-92

Ikeda, T (1970). Relationship between respiration rate and body size in marine plankton animals as a function of the temperature of habitat. Bull. Fac. Fish. Hokkaido Univ. 21: 91-112

Ikeda, T (1974). Nutritional ecology of marine zooplankton. Mem. Fac. Fish. Hokkaido Univ. 22: 1-97

Ikeda, T. (1985). Metabolic rates of epipelagic marine zooplankton as a function of body mass and temperature. Mar Biol. 85: 1-11

lvleva, I. V. (1973). Quantitative correlation of temperature and respiratory rate in poikilothermic animals. Polskie Arch. Hydrobiol. 20: 283-300

Ivleva, I. V. (1977). Metabolic rate of crustaceans living at low temperatures. Trudý vses. gidrobiol. Obshch. 22: 197-230 (Russian)

Ivleva, I. V. (1980). The dependence of crustacean respiration rate on body mass and habitat temperature. Int. Revue ges. Hydrobiol. 65: 1-47

Jobling, M. (1981). The influences of feeding on the metabolic rate of fishes: a short review. J. Fish Biol. 18: 385-400

Jobling, M. (1983). Towards an explanation of specific dynamic action (SDA). J. Fish Biol. 23: 549-555

Kiørboe, T., Møhlenberg, F., Hamburger, K. (1985). Bioenergetics of the plankton copepod Acartia tonsa: relation between feeding, egg production and respiration, and composition of specific dynamic action. Mar. Ecol. Prog. Ser. 26: 85-97

Klekowski, R. Z., Duncan, A. (1975). Physioiogical approach to ecological energetics. In: Grodzinski, W., Kliekowski, R. Z., Duncan, A. (ed.) Methods for ecological energetics. IBP Handbook No. 24. Blackwell, Oxford, p. 15-64

Koch, F., Wieser, W. (1983). Partitioning of energy in fish: can reduction of swimming activity compensate for the cost of production? J. exp. Biol. 107: 141-146

Levinton, J. S. (1983). The latitudinal compensation hypothesis: growth data and a model of latitudinal growth differentiation based upon energy budgets. I. Interspecific comparison of Ophryotrocha (Polychaeta: Dorvilleidae). Biol. Bull. mar. biol. Lab., Woods Hole 165: 686-698

Lonsdale, D. J., Levinton, J. S. (1982). Latitudinal differentiation in copepod growth: an adaptation to temperature. Ecology 66: 1397-1407

Luxmoore, R. A. (1982). The reproductive biology of some serolid isopods from the Antarctic. Polar Biol. 1: 3-11

Luxmoore, R. A. (1985). The energy budget of a population of the Antarctic isopod Serolis polita. In: Siegfried, W. R., Condy, P. R., Laws, R. M. (ed.) Antarctic nutrient cycles and food webs. Springer-Verlag, Berlin, p. 389-396

McNeill, S., Lawton, J. H. (1970). Annual production and respiration in animal populations. Nature, Lond. 225: $472-474$

Mishima, J., Odum, E. P. (1963). Excretion rate of $\mathrm{Zn}^{65}$ by Littorina irrorota in relation to temperature and body size. Limnol. Oceanogr. 8: 39-44

Parry, G. D. (1978). Effects of growth and temperature acclimation on metabolic rate in the limpet, Cellana tramoserica (Gastropoda: Patellidae). J. Anim. Ecol. 47: 351-368

Parry, G. D. (1983). The influence of the cost of growth on ectotherm metabolism. J. theor. Biol. 101: 453-477

Peck, L. S. (1983). An investigation into the growth and early development of the ormer, Haliotis tuberculata L. Ph. D. thesis, CNAA Portsmouth Polytechnic

Petrusewicz, K., Macfadyen, A. (1970). Productivity of terrestrial animals. Principles and methods. IBP Handbook No. 13. Blackwell, Oxford

Phillipson, J. (1966). Ecological energetics. Edward Arnold, London

Phillipson, J. (1975). Introduction to ecological energetics. In: Grodzinski, W., Klekowski, R. Z., Duncan, A. (ed.) Methods for ecological bioenergetics. IBP Handbook No. 24. Blackwell, Oxford, p. 3-13

Pianka, E. R. (1972). $r$ and $k$ selection or $b$ and $d$ selection? Am. Nat. 106: 581-588

Picken, G. B. (1979). Non-pelagic reproduction of some Antarctic prosobranch gastropods from Signy Island, South Orkney Islands. Malacologia 19: 109-128

Reznick, D. (1983). The structure of guppy life histories: the trade off between growth and reproduction. Ecology 64: $862-873$

Shumway, S. E., Perkins, H. C., Schick, D. F., Stickney, A. P. (1985). Synopsis of biological data on the pink shrimp, Pandalus borealis Kroyer, 1838. (FAO Fish. Synopses No. 144) NOAA Tech. Rep. NMFS 30

Sibly, R. M., Calow, P. (1986). Physiological ecology of animals. An evolutionary approach. Blackwell, Oxford

Tinkle, D. W., Hadley, N. F. (1975). Lizard reproductive effort; calorific estimates and comments on its evolution. Ecology 56: $427-434$

Torres, J. J., Childress, J. J. (1983). Relationship of oxygen consumption to swimming speed in Euphausia pacifica. 1. Effects of temperature and pressure. Mar. Biol. 74: 79-86

Torres, J. J., Childress, J. J., Quetin, L. B. (1982). A pressure vessel for the simultaneous determination of oxygen consumption and swimming speed in zooplankton. Deep Sea Res. 29: 631-639

Tuomi, J., Hakala, T., Haukioja, E. (1983). Alternative concepts of reproductive effort, costs of reproduction, and selection in life-history evolution. Am. Zool. 23: 25-34

Vahl, O. (1984). The relationship between specific dynamic action (SDA) and growth in the common starfish, Asterias rubens L. Oecologia (Berl.) 61: 122-125 